\title{
Abattoir as a Tool for Veterinary Extension and Communication Services: A Practical Demonstration of Its Implementation
}

\author{
Shehu AbdulQadir Zailani ${ }^{*}$ (), Sani Bello Nma², Nuhu Abubakar ${ }^{3}$, \\ Hassan Kanti Madu ${ }^{4}$, Ahmad Tijjani Tinau ${ }^{5}$
}

${ }^{1}$ Department of Animal Health Technology, Bauchi State College of Agriculture, Bauchi State, Nigeria

${ }^{2}$ Department of Animal Health, Niger State Ministry of Livestock and Fisheries, Minna, Niger State, Nigeria

${ }^{3}$ Department of Agricultural Extension and Management, Bauchi State College of Agriculture, Bauchi, Nigeria

${ }^{4}$ Department of Animal Health and Production Technology, Federal College of Horticulture, Dadin-Kowa, Gombe State, Nigeria

${ }^{5}$ Department of Animal Health Technology, College of Agriculture and Animal Science, Kaduna, Kaduna State, Nigeria

Email: *sazailani2@gmail.com

How to cite this paper: Zailani, S.A., Nma, S.B., Abubakar, N., Madu, H.K. and Tinau, A.T. (2019) Abattoir as a Tool for Veterinary Extension and Communication Services: A Practical Demonstration of Its Implementation. Open Journal of Veterinary Medicine, 9, 1-10.

https://doi.org/10.4236/ojvm.2019.91001

Received: January 3, 2019

Accepted: January 28, 2019

Published: January 31, 2019

Copyright $\odot 2019$ by author(s) and Scientific Research Publishing Inc. This work is licensed under the Creative Commons Attribution International License (CC BY 4.0).

http://creativecommons.org/licenses/by/4.0/

\begin{abstract}
Considering the widespread disease transmission among butchers/meat inspectors and a possible risk of exposure to diseases due to the attitude of some butchers and nature of meat inspector's jobs. Ignorance and lack of awareness of such dangers has also been identified to be responsible for some of the problems encountered in most instances as well as the presence of some predisposing factors for diseases. In view of the above, this model is developed as a means of demonstrating the use of the abattoir and other registered related slaughter premises in the provision of the physical facility, where the primary role of extension personnel to develop the capacity and capability of target groups in the abattoir and livestock producing community, in order to enhance animal/zoonotic disease surveillance and control. The model if adopted and fully utilized will create awareness among target groups of dangers of disease transmission and ways of curtailing such problems, government through their agencies, professionals and private organizations should be involved in the implementation of this model in order to achieve the desired response.
\end{abstract}

\section{Keywords}

Abattoir, Extension, Disease Transmission

\section{Introduction}

"Abattoir" means any premise that is approved and registered by the controlling 
authority in which fresh meat is prepared, handled, packed or stored, and in which animals are slaughtered and dressed for human consumption [1]. Apart from the statutory role of the abattoir mentioned above, Part (VIII) of the Meat Inspection and Hygiene of Nigeria [2], buttressed "the importance in animal disease surveillance, control and prevention" role of the abattoir in relation to disease reporting from States to the Federal Government.

Essentially, abattoir monitoring forms an essential part of disease surveillance, and also offers an opportunity to sample the meat offered for sale for human pathogens such as salmonellas and Escherichia coli [3]. Holding facilities at abattoirs and places where livestock are brought for sale (e.g. sales pens, auction yards, livestock markets) offers an opportunity to carry out visual inspection of live animals destined for sale. Disease often prompts owners to sell animals in order to reduce expected losses, and the animals may be showing clinical signs of disease when offered for sale.

Meat has traditionally been viewed as a vehicle for a significant proportion of human food-borne disease [4]. Although the spectrum of meat-borne diseases of public health importance has changed with changing production and processing systems, continuation of the problem has been well illustrated in recent years by human surveillance studies of specific meat-borne pathogens such as Escherichia coli O157: H7, Salmonella spp., Campylobacter spp. and Yersinia enterocolitica [4]. The Codex also stated that in addition to existing biological, chemical and physical hazards, new hazards are also appearing and they include the agent of bovine spongiform encephalopathy (BSE). Furthermore, consumers have expectations about suitability issues which are not necessarily of human health significance [4].

The veterinary services should be able to describe what important diseases are present, and detect the occurrence of important new, emerging or exotic diseases. Nevertheless, a country that is implementing a control program for endemic or epidemic disease needs more information from surveillance than can be gathered from the basic two requirements listed above [3]. In many cases, weaknesses in a national disease surveillance system are due more to resource constraints than a lack of planning or understanding of surveillance programmes [3]. In recent times, Nigeria's limited and poorly managed resources have lead to the neglect of disease surveillance. Nonetheless, some developing countries like Ethiopia, India and Uganda place great emphasis on Extension and Communication programmes or modules to complement and sustain disease reporting through participatory disease surveillance/epidemiology. This enables, amidst strained financial resources, the introduction of new findings on the prevention and control of these diseases to the benefit of the general public.

The general concept of extension is a function of providing the required and demand-based knowledge and skills for rural men, women and youth in a non-formal, participatory manner with the objective of enhancing their capacity to undertake farming operations to improve productivity and quality of life [5]. 
Over time it promotes the transfer and exchange of information that can be converted into functional knowledge to develop enterprises for promoting productivity and generating income [6].

With focus on business and information dissemination, the abattoirs are a central point for innovation and learning in community-owned and managed livestock enterprises. Its vision is to be an active partner in livestock businesses and in the transformation of the livestock value chain in Africa, serving the livestock keepers while delivering high quality of meat produced in a sustainable way to urban markets, and can therefore serve as means of information and communication of certain issues such as hygiene, disease prevention and control [7].

This paper is aimed at demonstrating the use of the abattoir, a registered premise, in the provision of the physical facility, where the primary role of extension personnel to develop the capacity and capability of target groups in the abattoir and livestock producing community, in order to enhance animal/zoonotic disease surveillance and control, takes place.

\section{Case Study (Extension Problem)}

Although the first case of human brucellosis confirmed by serological tests in Nigeria was in 1941 and 1962, studies [8] have shown in the last ten years a high prevalence in abattoir workers in Abuja Nigeria with a seroprevalence figures of $24.1 \%$ among 224 workers where $172(76.8 \%)$ were male (mean age of $30+9.0$ years). Some of the risk factors associated with this high prevalence were slaughtering while having open wounds, occupational exposure of 5 years and eating raw meat. In response to this report, the State Governments met with members of the Butcher's Association of Nigeria (BAN) and interpreted the report to them.

The implication of the problem was made clear to BAN and the need for Abattoir workers and other workers in the abattoir, to take preventive measures against contracting this avoidable zoonotic disease was emphasised. To reach out to the entire abattoir community and livestock traders in all the abattoirs at Local Government Areas (LGAs) of a State, an Extension and Communication Programme (ECP) should be proposed by the Department of Veterinary Public Health and Epidemiology to educate occupationally-at-risk groups on the transmission, risk factors, detection and prevention of brucellosis.

\subsection{Programme Caption: Infectious/Zoonotic Diseases Sensitisation and Awareness Education}

This would incorporate the philosophy and principles of extension and communication as a template for the sensitisation and awareness education initiative of the department.

\subsection{Objectives}

1) To disseminate practical information on the cause, transmission and prevention of infectious/Zoonotic diseases among occupationally exposed groups. 
2) To educate the target group on the risk factors associated with such diseases.

3) To create attitudinal change with regards to exposure to such diseases in occupationally-at-risk groups.

4) To assess the impact of the extension program on the target groups.

\subsection{Initial Knowledge Appraisal of the Subject Matter}

In order to prioritise the set objectives, a published report of the Knowledge, Attitude and Practice (KAP) assessment of the case study is first made. The KAP assessment of brucellosis in Osun State would serve as the bench mark. The result of the study revealed that a high percentage of respondents among occupationally exposed groups are ignorant of the cause, transmission and awareness of the disease [9].

\section{Extension Teaching Approach}

\subsection{The Group Method}

The type of approach to be used in extension work will depend primarily on policy considerations, including the clientele to be served, the mission of extension, and financial considerations. In addition, the type of approach to be adopted will directly affect how programmes are delivered at the field level [10]. For this programme the General Meeting approach would be used since BAN and other interest groups are the target population for the extension programme. The type of meeting to be employed would be Special Interest Meetings (SIM) which are engaged to serve the educational needs of groups with common interests such as the occupationally at-risk-groups exposed to such infectious/Zoonotic diseases. These meetings would initially be held singly and in series over a period of time.

It is imperative for the extension and communication agent to fully appreciate the fact of interaction of the elements of learning depicted above. It clearly shows that the entire orbit revolves around the learner. Invariably, the learner is the main aim of the extension model through which the other four factors interact to achieve a set goal. The less abstract these methods are, the more the learner will participate, and the more effective will be the educational experience.

For example, if farmers are not performing a task effectively, then it will be much more effective to organize a method demonstration than a lecture or group meeting. In this context, the brucellosis awareness campaign requires the development of two major parts of the learning element. These are the subject matter which demands tactical application of extension learning and the correct selection of the most suitable teaching materials which is systematic.

\subsection{Composition of Learners}

A typical Nigerian abattoir is a heterogeneous community that interact with one another to create a socioeconomic interdependent balance. Consequently, learners 
in this community are delineated based on their nature of job within the abattoir. These occupational groups include: Veterinarians, para-veterinarians, abattoir management staff, butchers, meat-sellers, slaughterers, herdsmen, animal loaders, cleaners, food hawkers and members of the general who come for direct purchase of different animal products sold in the abattoir. All these groups mentioned above are at the risks of exposure to infectious/zoonotic diseases.

\section{Framework for Planning and Implementation of the Extension Delivery}

\section{Stage 1: Determining, developing and prioritizing of appropriate content}

This stage address's the options to be presented to the target groups by the extension planners/administrators on the extension subject matters. These options would be tabled at the meeting with the target groups.

1) Such subject matter options to be addressed include:

a) Identifying and assessing needs, wants and interest of target groups with regard to the subject matter of the extension exercise.

b) Identifying unhygienic practices in the abattoir.

c) Implication of waste disposal and environmental contamination of abattoir premises and environs.

d) Appreciation of the use of protective clothing.

e) Implication of the role of members of the abattoir community in the extension program.

f) Discussing and underscoring the sustainability of the programme.

2) Decide on and secure speakers

3) Arrange for social and recreational aspects of the meeting

4) Agree on the place and time of the meeting

5) Select the chairman of the meeting and advertise the meeting

6) Agree on the topic to be discussed

Stage 2: Meeting with BAN leaders and other stake holders in the abattoir community

1) Present a formal official letter from the Director of Veterinary Public Health and Epidemiology (since all State Abattoir Meat Inspectors belong to his department) to the Chairman of BAN. The letter should be concise and spell out the objective and benefits of the program.

2) Meet in person with BAN executives and agree on the purpose of the meeting.

3) Agree on the date and time of a group meeting with all BAN executives and possible faction leaders within the abattoir to draw up tentative program and decide on a representative from their part.

4) Let BAN members select the chairman and secretary for the extension program.

5) Let other target groups as indicated in the composition of learners above select their own representatives. 
6) Advertise the meeting through banners, personal contacts and constant reminders of the BAN selected extension officials.

7) Make arrangement for entertainment and light recreation at the meeting.

\section{Stage 3: Program delivery and implementation strategies}

Extension's clientele is a heterogeneous group of people differentiated by resources, gender, age, and ethnicity. Communication theories indicate that the trickle-down effect of agricultural innovations rarely takes place among heterogeneous groups, and when it occurs, it does so at an extremely slow pace. Given this understanding, it is therefore imperative to identify homogeneous categories within those groups of clientele in order to facilitate the effective transfer of technology [10].

The strategy is therefore to develop homogeneous groups of clientele to target extension programmes. Hence for the success and ensured continuity of the programme, association heads within the abattoir have been identified. [11] contends that, extension programmes should then be developed for each of the targeted categories. Invariably, a module would be packaged to take into cognisance the risk of exposure of each member of the heterogeneous group in the abattoir community as revealed by various studies. The teaching method selected for the learners would be assessed in line with guidelines for adoption process of the extension programme. Thus, in the group meetings for instance, the extension officer can use a lecture format, supported with a video, and followed with group discussions.

\section{Stage 4: Extension programme evaluation}

The other important consideration in selecting methods for the delivery of appropriate content is an understanding of the adoption process. It is opined that the adoption process consisted of five distinct stages: awareness, interest, evaluation, trial, and adoption. Accordingly, the individual in the process goes through each stage within a definable time period. Later works in extension studies however, have shown that these stages are not as distinct as the first proposal and that some of the stages may become condensed within the individual cognitive processes. This makes them unrecognizable as a behaviour which can be measured over time [10].

With regard to this particular awareness campaign, it should be understood that the awareness, interest and evaluation stages are critical to the context of the outlined goal of this extension programme. It is imperative to appreciate the difficulty of demonstrating the danger posed by brucellosis as it is practised in the traditional agrarian extension contest where for instance, a new farming technique is demonstrable. In our instance, the insidious and deleterious consequences of brucellosis may end up to be an abstract phenomenon if a meticulous subject matter plan and teaching materials are not envisioned. Hence, the success of this programme would be based on the conviction provided by the teaching method generally. Hence, the teaching method shall emphasis the impact of brucellosis on livestock and humans' endemic areas using graphical 
teaching aids: power point presentations, posters, short documentaries among others.

Evaluation is the most critical stage in the adoption process, because the outcome usually determines whether or not individual's proceeds' to the trial and adoption stages. At this stage, people need to match knowledge against facts. These types of experiences allow for the removal of doubts [10]. In evaluating the adoption of this programme, attitudinal change is what is required. This would involve both pre-test and post-test evaluation of the programme. The pre-test assessment would be noted during the group discussion stage. The awareness and interest of the groups involved would be measured based on their level of participation in sharing their knowledge of the disease and perception of its dangers to the health of the individual.

A practical pre-test assessment can also be made for instance, by gauging their willingness to participate in a sero-surveillance study of the disease among abattoir workers. Based on the outcome of a sero-surveillance, a post-test analysis would involve the assessment of members of the various groups to demand for the result of serological tests made. Where positive results emerge, the conviction that the programme is progressing could be based on the demand of members of the groups for prescription drugs in the event positive cases. Their adoption of personal prevention methods and environmental sanitation practices, especially their willingness to down self-acquired protective gears would a good parameter for assessing attitudinal change.

\section{Discussion}

The entire component $s$ of extension learning situation (Figure 1) comprises of the instructor who is at the top and is the meat inspector (veterinarian, animal scientist or livestock superintendent). For effective function of the instructor he need to be at the abattoir (or any registered slaughter premises) and the end user or learners or the at risk groups also present, with that the subject matter will be discussed extensively to create awareness to the end users on issues such as causes and routes of disease transmission, consequences of contracting most of such diseases encountered at the abattoirs and the recommended preventive measures. Also for effectiveness of the butcher's awareness campaign certain teaching/learning materials need to be available such as power point projector for presentation or video player and television set for film presentation.

The use of group method combine with Audio-visual for this particular model is deliberately selected for it will be effective considering the target audience composition i.e. comprising of the abattoir workers who are mostly enlightened while the butchers in most instances are not. In view of the above the group method will create an avenue or an opportunity for an effective discussion among the participants or the end users where a lot of questions/discussions are expected to be generated and handled by the instructors with the contribution of experiences participants. 


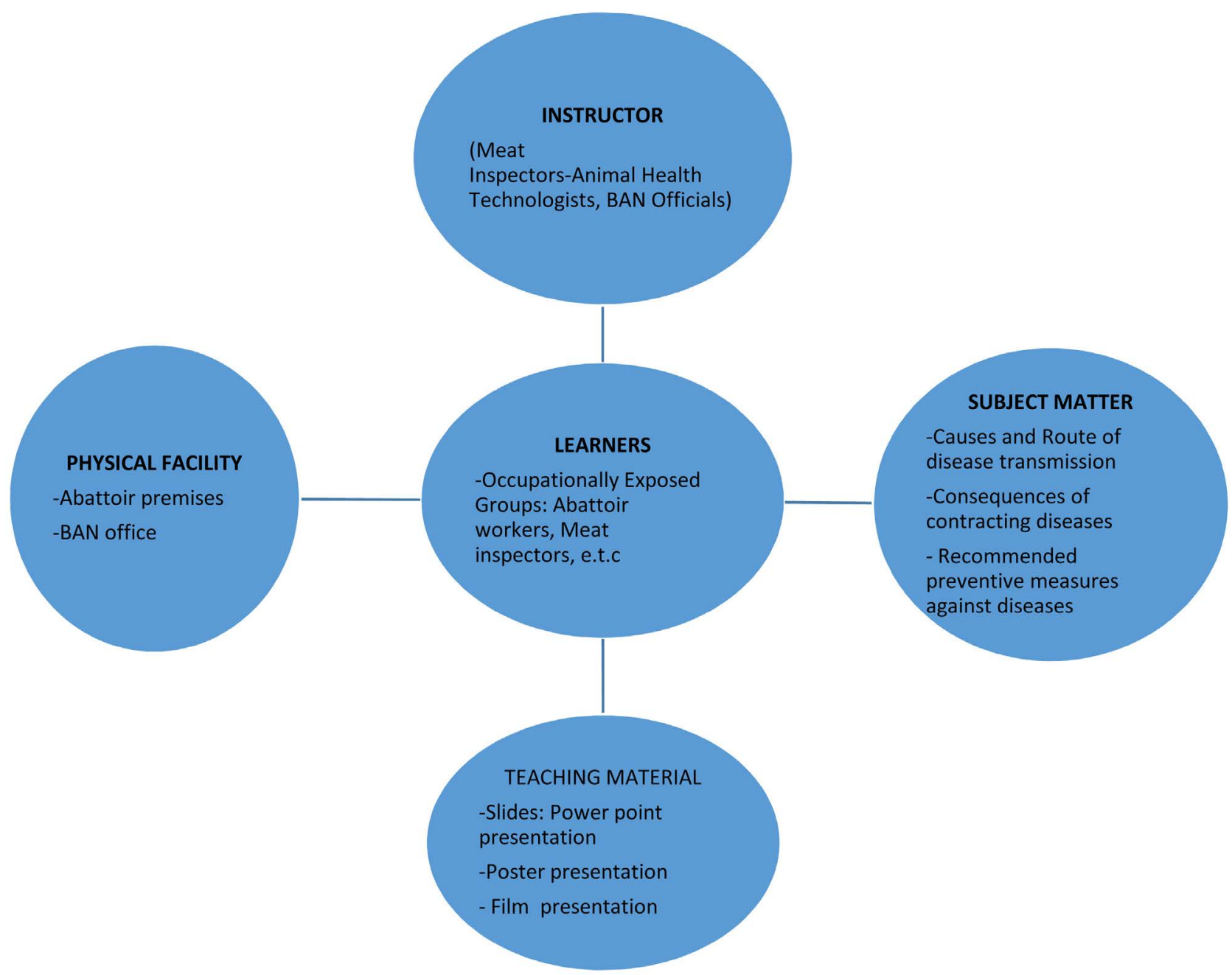

Figure 1. Components of the extension learning situation for brucellosis awareness campaign.

\section{Conclusion and Recommendation}

Abattoir monitoring of diseases forms an essential part of disease surveillance in the world. In Nigeria, the abattoir is a centre spot of a highly integrated heterogeneous community in which socioeconomic activity revolve around the sales of live animals, their products and by-products. This interaction between animals and people increases the risk of exposure to zoonoses. One of the most important aspects of control of zoonoses is public education and enlightenment. This aspect is a component of veterinary extension and communication. This paper highlighted the application of veterinary extension and communication techniques in the planning and implementation of an awareness campaign on dangerous occupational, infectious/zoonotic diseases. However, despite the practicability of this approach, a major challenge to its sustainability depends, to a large extent, on the ability of abattoir administrative authorities to play their regulatory and operational role in the management of abattoirs.

This model should be applied practically by extension agents in state ministries of animal resources or any relevant organizations overseeing the activities 
of slaughter houses, and it will go a long way in tracking diseases at the abattoirs. The advantages of this model include among others creating awareness to abattoir workers on dangers of zoonotic/infectious diseases. The model will also suggest preventive measures as such reducing number of individuals that may ordinarily without the program will contract such occupational diseases, as a result of the economy of the workers will improve by reducing the cost of treating such diseases if contracted. The model will also help in the surveillance of many infections and zoonotic diseases and subsequently help in safeguarding the health of the general public. The efficiency of this model can also be assessed by assigning it to students or researchers to practically employ it, also tracking and assessing some diseases at the abattoir.

\section{Conflicts of Interest}

The authors declare no conflicts of interest regarding the publication of this paper.

\section{References}

[1] FAO/WHO (1993) Joint Food and Agriculture Organisation and World Health Organization of the United Nations Food Standards Programme. Codex Alimentarius Commission 20 th Session, Geneva, 28 June-7 July 1993.

[2] Meat Inspection and Hygiene of Nigeria (2008) Midi-Brief Transforming the Nigerian Red Meat Industry, Products (SON), Draft Meat Inspection and Hygiene Act 2008 of the Federal Government of Nigeria.

[3] AU-IBAR (2012) Manual of Basic Animal Disease Surveillance. African Union-Inter African Bureau for Animal Resources (AU-IBAR), Nairobi Kenya. http://www.au-ibar.org/

[4] CAC/RCP (2005) Codex Alimentarius Code of Hygiene Practice for Meat CAC/ RCP 58-2005. http://www.fao.org/downloads/standards

[5] Qamar, M.K. (2002) Global Trends in Agricultural Extension: Challenges Facing Asia and the Pacific Region. Paper presented at the FAO Regional Expert Consultation on Agricultural Extension, Research-Extension-Farmer Interface and Technology Transfer, held in Bangkok, Thailand, July 16-19, 2002. Rome: Research, Extension and Training Division. Sustainable Development Department, FAO.

[6] World Bank (2004) Decentralized Systems: Case Studies of International Initiatives: Volume 1. In: Rivera, W. and Alex, G., Eds., Agriculture and Rural Development Discussion Paper 8. Extension Reform for Rural Development, World Bank, Washington DC.

http://siteresources.worldbank.org/INTARD/8258261111129171182/20431831/Exte nsion_Reform_V1_final.pdf

[7] Keekonyokie (2005) Linking Community Slaughter Houses with Urban Markets, http://www.ravinvest.biz/downloads/story60_kibue_ChallengesforkeekonyokieMA C.pdf

[8] Aworh, M.K., Okolocha, E.C., Kwaga, J., Fasina, F., Lazarus, D., Suleiman, I., Poggensee, G., Nguku, P. and Nsubuga, P. (2013) Human Brucellosis: Seroprevalence and Associated Factors among Abattoir Workers in Abuja, Nigeria-2011.

[9] Adesiji, Y.O., Adesiji, G.B. and Fagbami, A.H. (2005) Brucellosis: Knowledge, Atti- 
tude and Practices among Occupationally Exposed Individuals in Osun State. Science Focus, 10, 38-41.

[10] Swanson, B.E., Bentz, R.P. and Sofranko, A.J. (Editors) (1998) Improving Agricultural Extension: A Reference Manual. Food and Agriculture Organization of the United Nations, Rome.

[11] Swanson, B.E. (1984) Agricultural Extension: A Reference Manual. Food and Agriculture Organisation, Rome.

\section{Abbreviations}

AU-IBAR-African Union-Inter-African Bureau for Animal Resources

BAN-Butchers Association of Nigeria

BSE-Bovine Spongiform Encephalitis

CAC-Codex Alimentarius Commission

ECP-Extension and Communication Programme

FAO_Food and Agriculture Organization

FSP-Food Security Program

KAP - Knowledge Attitude Practice

$\mathrm{RCP}$-Recommended international Code of Practice

SIM-Special Interest Meetings

WHO-World Health Organization 